\title{
IMAGEM DO BRASIL E ATITUDES DOS CONSUMIDORES SUL-AFRICANOS
}

BRAZIL'S IMAGE AND ATTITUDES OF SOUTH AFRICAN CONSUMERS

\author{
Recebido em 22.11.2015. Aprovado em 16.02.2016 \\ Avaliado pelo sistema double blind review \\ DOI: http://dx.doi.org/10.12712/rpca.v10i1.694
}

\section{Harrison Bachion Ceribeli \\ harrisonbceribeli@yahoo.com.br \\ Universidade Federal de Ouro Preto (UFOP), Ouro Preto/MG, BRASIL}

\section{Natália Brito Zuca de Souza}

nataliabritozuca@gmail.com

Universidade Federal de Ouro Preto (UFOP), Ouro Preto/MG, BRASIL

\section{Resumo}

Esta pesquisa teve como objetivo analisar o efeito que a imagem do Brasil exerce sobre as atitudes dos consumidores sul-africanos em relação às roupas e calçados de origem brasileira. Para coleta de dados, realizou-se um levantamento de campo. A amostra de pesquisa foi composta por habitantes da cidade de Stellenbosch, África do Sul. Para análise dos dados, foram utilizadas duas técnicas estatísticas: Análise Fatorial Exploratória e Análise de Regressão Múltipla. Com base nos resultados, constatou-se que o efeito país de origem que a imagem brasileira exerce sobre os consumidores sul-africanos influencia suas atitudes no nível cognitivo, no segmento de calçados, e nos níveis cognitivo, afetivo e conativo, no segmento de vestuário. Tal constatação evidencia que, para que a indústria da moda brasileira consiga efetivamente penetrar na África do Sul, é importante que haja um esforço consciente e direcionado para formar nos consumidores de lá uma imagem positiva a respeito do Brasil.

Palavras-chave: Efeito país de origem. Indústria brasileira da moda. Mercado da África do Sul. Segmento de calçados. Segmento de vestuário.

\begin{abstract}
This research aimed to analyze the effect that the image of Brazil has on the attitudes of South African consumers in relation to Brazilian clothing and shoes. For data collection, we conducted a field survey. The research sample consisted of inhabitants of the town of Stellenbosch, South Africa. For data analysis, two statistical techniques were used: Exploratory Factor Analysis and Multiple Regression Analysis. Based on the results, it was found that the country of origin effect that Brazil's image has on South African consumers influence the attitudes of these consumers in cognitive level, in the footwear segment, and in the cognitive, affective and conative levels, in the clothing segment. This finding shows that, for the Brazilian fashion industry can effectively penetrate in South Africa, it is important there is a conscious and directed effort to form a positive image about Brazil among South African consumers.
\end{abstract}

Keywords: Country of origin effect. Brazilian fashion industry. South African market. Footwear market. Clothing market. 


\section{Introdução}

Entre as características da globalização, destaca-se o fato de que os fluxos financeiro, informacional e de produtos ultrapassaram toda e qualquer fronteira geográfica. E, à medida que se avançava rumo à consolidação desse fenômeno, os limites territoriais dos países deixaram de ser vistos como obstáculos intransponíveis para a realização de transações comerciais. Consequentemente, surgiram inúmeras oportunidades para explorar, a nível internacional, diferentes mercados consumidores.

Impulsionadas pela proliferação de tais oportunidades, várias empresas brasileiras, atuando em setores diversos, passaram a comercializar seus produtos em mercados localizados em outros continentes, tais como América do Norte, América Central, Ásia e África, almejando expansão dos negócios, projeção internacional, aumento da lucratividade e redução de riscos associados aos ciclos econômicos do Brasil.

Especificamente no continente africano, existe um mercado potencial ainda pouco explorado pelas empresas brasileiras, por questões que extrapolam o escopo deste trabalho. Todavia, nos últimos anos, tem crescido o volume de transações comerciais envolvendo empresas nacionais e mercados africanos.

Segundo a Agência Brasileira de Promoção de Exportações e Investimentos (APEX), entre 2002 e 2012, as transações comerciais envolvendo Brasil e África aumentaram 410\%, e, entre 2004 e 2014, as exportações nacionais para países africanos cresceram 131\% (PEDUZZI, 2015).

À margem desse quadro, a indústria da moda brasileira ainda não conseguiu consolidar-se entre os principais players exportadores do Brasil para o continente africano, ou seja, existe um mercado potencial na África a ser explorado pelas empresas nacionais de vestuário e calçados.

Entretanto, para que as investidas da indústria da moda brasileira nos países da África sejam bem sucedidas, é preciso entender o comportamento dos consumidores africanos, o que envolve, dentre outros aspectos, analisar o efeito que a imagem do Brasil exerce sobre as atitudes desses consumidores em relação às roupas e calçados de origem brasileira, sendo esse o objetivo da presente pesquisa, limitado, todavia, aos consumidores sul-africanos.

Cabe esclarecer que esse estudo limitou-se aos sulafricanos, à medida que a África do Sul é um dos principais países do continente africano, considerandose, entre outros critérios, o Produto Interno Bruto (PIB) desse país em relação aos outros localizados no mesmo continente.

\section{Efeito país de origem}

A informação a respeito do país de origem de um produto tende a ser interpretada pelos consumidores como um sinal extrínseco de suas características e desempenho; por isso, o país de origem é considerado um atributo intangível, que exerce influência sobre o processo de decisão de compra, por meio de um fenômeno que se convencionou denominar efeito país de origem (MEHMET; PIRTINI; ERDEM, 2010; BILKEY; NES, 1982).

Segundo Nagashima (1970), o conceito de efeito país de origem refere-se à transferência da imagem, reputação e estereótipos que os consumidores associam a determinado país aos produtos que lá são fabricados. Esse processo cognitivo pode ser compreendido à luz dos estudos nos campos da psicologia e do comportamento do consumidor sobre categorias mentais, que defendem que os indivíduos, ao analisarem dado objeto, fazem-no a partir de categorias mentais pré-estabelecidas. Partindo desta perspectiva, o efeito país de origem pode ser conceituado como um processo cognitivo por meio do qual os consumidores, na ausência de informações mais detalhadas, avaliam determinado produto a partir do conjunto de percepções que eles possuem a respeito do país em esse produto foi produzido (AGARWAL; SIKRI, 1996; LEE; GANESH, 1999).

Neste sentido, percebe-se que a informação acerca do país de origem dos produtos pode atuar como um fator simplificador na avaliação do consumidor (KUMARA; CANHUA, 2010), que, ao entrar em contato com determinado produto, tende a avaliá-lo de maneira negativa, caso este tenha sido fabricado em um país cuja imagem esteja associada a bens de qualidade duvidosa (SAMILI, 2013).

Cabe acrescentar que a imagem de um país está atrelada não apenas à percepção generalizada dos indivíduos referente à qualidade dos produtos lá fabricados, mas também a aspectos como grau de desenvolvimento econômico, estrutura e maturidade política, cultura e tradições, avanços tecnológicos, nível de industrialização, conflitos com outros 
países, condições de trabalho e questões ambientais (CANTO-GUINA; GIRALDI, 2012; ROTH; DIAMANTOPOULOS, 2009).

O efeito que a imagem do país onde determinado produto foi fabricado exerce sobre a avaliação feita pelos consumidores tem sido objeto de estudo nas últimas décadas devido ao impacto que causa sobre a intenção de compra (KABADAYI; LERMAN, 2011), o que se explica pelo fato de que os indivíduos podem associar mais riscos à compra de produtos de países com imagem negativa, ou podem tentar melhorar seu status por meio da aquisição de produtos provenientes de países com imagem positiva (CORDELL, 1993).

Tal afirmação é corroborada por Silva et al. (2015), que constataram que a intenção de compra de um produto tende a ser maior caso este seja projetado, montado ou produzido em um país cuja imagem seja positiva e esteja associada à maior expertise produtiva. Do mesmo modo, a intenção de compra de um produto tende a ser maior quando os insumos ou componentes utilizados em sua fabricação são provenientes de países com imagem mais favorável no mercado (SILVA et al., 2015).

O efeito país de origem ainda explica o fato de que consumidores que sentem animosidade em relação a determinado país tendem a evitar produtos que tenham sido fabricados lá, independentemente de sua avaliação relativa àqueles mesmos produtos (HOFFMANN; MAI; SMIRNOVA, 2011; AMINE, 2008; HONG; KANG, 2006).

Do mesmo modo, pode-se observar a influência do efeito país de origem sobre os consumidores cujas decisões são influenciadas pelo etnocentrismo, que tendem a dar preferência aos produtos fabricados em seu próprio país, independentemente da avaliação que fazem acerca da qualidade dos mesmos (POON; EVANGELISTA; ALBAUM, 2010). Tal comportamento se explica com base no fato de que estes consumidores tendem a se sentirem desconfortáveis ao adquirirem produtos importados pela crença de que isso afeta negativamente a economia local, causa desemprego e é um sinal de antipatriotismo (SHIMP; SHARMA, 1987). Especificamente no setor de vestuário, Lee, Phau e Roy constataram que os consumidores com elevado grau de etnocentrismo percebem as roupas íntimas fabricadas em seu próprio país e com marcas nacionais como sendo mais duráveis, com melhores preços, mais atrativas, com mais opções de cores e estilos.
Além de influenciar a intenção de compra dos indivíduos, o efeito país de origem também afeta a disposição daqueles de pagar preços mais ou menos elevados para adquirir determinados produtos, sendo que preços mais elevados tendem a ser mais aceitos quando o produto foi fabricado em um país que possui boa reputação, enquanto preços menores são esperados de produtos produzidos em países com pouca tradição no mercado ou que possuem uma imagem negativa (HAN, 2010; DROZDENKO; JENSEN, 2009). Tal constatação confirma os resultados obtidos por Hulland, Todiño e Lecraw (1996), que concluíram que os consumidores estão dispostos a pagar mais caro por produtos provenientes de países altamente industrializados, à medida que associam estes a maior nível de qualidade.

O efeito país de origem também influencia as atitudes dos consumidores, seja por meio da imagem cognitiva que estes nutrem em relação ao país onde determinados produtos foram fabricados, ou ainda por meio da imagem afetiva que os consumidores possuem desse mesmo país (PHILLIPS; ASPERIN; WOLFE, 2013).

Em seu estudo, Phillips, Asperin e Wolfe (2013) constataram que os consumidores terão atitudes mais positivas em relação a dado produto estrangeiro, se a imagem do país de origem for positiva. Cabe ressaltar que as atitudes dos consumidores frente a produtos estrangeiros tendem a ser intensificadas em uma aliança de marcas, quando as duas marcas, hospedeira e associada, vêm de algum país com imagem favorável (LEE; LEE; LEE, 2013).

Recentemente, diversos pesquisadores têm dedicado seus estudos a explorar como o efeito país de origem afeta as decisões de consumo. Dentre eles, destacam-se Godey et al. (2012), que constataram que, dependendo do segmento do produto (luxo ou não luxo) e do país do consumidor, tal influência tende a ocorrer em diferentes níveis (em alguns países, tais como China e Rússia, os indivíduos estão mais suscetíveis à influência do efeito país de origem).

Por sua vez, Giraldi e Carvalho (2009) verificaram que o efeito país de origem influencia a intenção de compra dos consumidores holandeses em relação a quatro categorias de produtos brasileiros: carne bovina, frutas frescas, calçados e móveis. Já Parkvithee e Miranda (2012) concluíram que, no segmento da moda, produtos cuja compra envolve baixo envolvimento do consumidor (tais como camisetas) 
e marcas pouco conhecidas no mercado tendem a ser avaliados de forma mais favorável e a ser associados à maior intenção de compra, caso sejam provenientes de países com imagem positiva.

Silva et al. (2015), ao investigarem o mercado de vinhos, concluíram que existe uma tendência de os consumidores avaliarem de forma mais positiva a qualidade dos vinhos provenientes de países com estereótipos positivos (no caso, os vinhos chilenos). Complementarmente, Berry et al. (2015) identificaram que os consumidores tendem a avaliar de forma mais positiva a qualidade das carnes (utilizando atributos como sabor, segurança e frescor) provenientes de frigoríficos norte-americanos do que de frigoríficos mexicanos ou sem informação de origem. Já Phillips, Asperin e Wolfe (2013) constataram que consumidores que nutrem uma imagem positiva da Coréia terão mais atitudes positivas para consumir comida coreana. Nesta mesma linha, Lee, Lee e Lee (2013) apontaram que indivíduos que associam o Japão à confiabilidade no segmento de eletrônicos tendem a apresentar atitudes mais positivas a veículos lá produzidos.

Analisando as pesquisas de Giraldi e Carvalho (2009), Parkvithee e Miranda (2012), Godey et al. (2012), Phillips, Asperin e Wolfe (2013), Lee, Lee e Lee (2013) e Berry et al. (2015) e Silva et al. (2015), verifica-se que, apesar de terem como foco segmentos de produtos diversos e terem sido realizadas em países diferentes, todas evidenciam o impacto que o efeito país de origem causa sobre a avaliação dos consumidores referente à qualidade dos produtos, suas atitudes e sua intenção de compra.

\section{Aspectos Metodológicos}

Para atingir o objetivo proposto, optou-se pela realização de um levantamento de campo. Para a coleta de dados, utilizou-se um questionário autoadministrado, estruturado com base na escala de Likert de cinco pontos.

O questionário utilizado foi dividido em quatro seções: a primeira incluiu cinco questões demográficas para caracterização da amostra; a segunda foi composta por 21 questões para mensurar a imagem que os consumidores sul-africanos possuem do Brasil, retiradas e traduzidas do estudo de Giraldi e Carvalho (2009); a terceira seção incluiu 11 questões para mensurar as atitudes dos consumidores sul- africanos em relação a calçados brasileiros, adaptadas e traduzidas a partir do questionário elaborado por Giraldi, Ikeda e Carvalho (2008); por fim, a última seção incluiu 11 questões para mensurar as atitudes desses mesmos consumidores em relação a peças brasileiras de vestuário, também adaptadas e traduzidas do questionário utilizado por Giraldi, Ikeda e Carvalho (2008). As questões de pesquisa e os nomes das respectivas variáveis podem ser visualizados no Quadro 01.

Quadro 1: Questões de pesquisa x variáveis de pesquisa

\begin{tabular}{|c|c|c|}
\hline Constructo & Questão de pesquisa & $\begin{array}{l}\text { Variável de } \\
\text { pesquisa }\end{array}$ \\
\hline \multirow{6}{*}{$\begin{array}{l}\text { Avaliação dos } \\
\text { produtos }\end{array}$} & $\begin{array}{l}\text { Em geral, os produtos } \\
\text { brasileiros são confiáveis. }\end{array}$ & AvProd1 \\
\hline & $\begin{array}{l}\text { Em geral, os produtos } \\
\text { brasileiros representam } \\
\text { boa qualidade pelo que se } \\
\text { paga. }\end{array}$ & AvProd 2 \\
\hline & $\begin{array}{l}\text { Em geral, os produtos } \\
\text { brasileiros duram bastante. }\end{array}$ & AvProd3 \\
\hline & $\begin{array}{l}\text { As empresas brasileiras } \\
\text { são confiáveis. }\end{array}$ & AvProd4 \\
\hline & $\begin{array}{l}\text { Em geral, os produtos } \\
\text { brasileiros são } \\
\text { tecnicamente avançados. }\end{array}$ & AvProd5 \\
\hline & $\begin{array}{l}\text { O Brasil possui } \\
\text { habilidades técnicas. }\end{array}$ & AvProd6 \\
\hline \multirow{4}{*}{$\begin{array}{l}\text { Avaliação das } \\
\text { artes }\end{array}$} & $\begin{array}{l}\text { O Brasil é importante } \\
\text { no cenário artístico } \\
\text { internacional. }\end{array}$ & AvArt1 \\
\hline & $\begin{array}{l}\text { O Brasil possui } \\
\text { habilidades artísticas. }\end{array}$ & AvArt2 \\
\hline & $\begin{array}{l}\text { Os brasileiros são } \\
\text { competentes nas artes. }\end{array}$ & AvArt3 \\
\hline & $\begin{array}{l}\text { Em geral, os produtos } \\
\text { brasileiros são criativos. }\end{array}$ & AvArt4 \\
\hline \multirow{4}{*}{$\begin{array}{l}\text { Respeito e } \\
\text { importância } \\
\text { do Brasil }\end{array}$} & $\begin{array}{l}\text { O Brasil é respeitado na } \\
\text { economia mundial. }\end{array}$ & Respe1 \\
\hline & $\begin{array}{l}\text { O Brasil é importante para } \\
\text { a economia mundial. }\end{array}$ & Respe2 \\
\hline & $\begin{array}{l}\text { O Brasil é respeitado na } \\
\text { política internacional. }\end{array}$ & Respe3 \\
\hline & $\begin{array}{l}\text { O Brasil é importante } \\
\text { no cenário político } \\
\text { internacional. }\end{array}$ & Respe4 \\
\hline
\end{tabular}




\begin{tabular}{|c|c|c|}
\hline \multirow{4}{*}{$\begin{array}{l}\text { Avaliação da } \\
\text { comunicação } \\
\text { e distribuição }\end{array}$} & $\begin{array}{l}\text { Em geral, os produtos } \\
\text { brasileiros são facilmente } \\
\text { encontrados. }\end{array}$ & AvCom1 \\
\hline & $\begin{array}{l}\text { Em geral, os produtos } \\
\text { brasileiros são } \\
\text { intensamente anunciados. }\end{array}$ & AvCom2 \\
\hline & $\begin{array}{l}\text { Em geral, os produtos } \\
\text { brasileiros são vendidos } \\
\text { em muitos países. }\end{array}$ & AvCom3 \\
\hline & $\begin{array}{l}\text { Em geral, a propaganda } \\
\text { dos produtos brasileiros é } \\
\text { informativa. }\end{array}$ & AvCom4 \\
\hline \multirow{3}{*}{$\begin{array}{l}\text { Afeto para } \\
\text { com o Brasil }\end{array}$} & $\begin{array}{l}\text { Eu tenho simpatia pelo } \\
\text { Brasil. }\end{array}$ & AfetB1 \\
\hline & Eu gosto do Brasil. & AfetB2 \\
\hline & Eu admiro o Brasil. & AfetB3 \\
\hline \multirow{4}{*}{$\begin{array}{l}\text { Atitudes } \\
\text { cognitivas } \\
\text { calçados }\end{array}$} & $\begin{array}{l}\text { Os calçados brasileiros } \\
\text { possuem boa reputação. }\end{array}$ & CogS1 \\
\hline & $\begin{array}{l}\text { Os calçados brasileiros são } \\
\text { caros. }\end{array}$ & CogS2 \\
\hline & $\begin{array}{l}\text { Os calçados brasileiros } \\
\text { têm prestígio. }\end{array}$ & $\operatorname{Cog} \mathrm{S} 3$ \\
\hline & $\begin{array}{l}\text { Os calçados brasileiros são } \\
\text { de alta qualidade. }\end{array}$ & CogS4 \\
\hline \multirow{4}{*}{$\begin{array}{l}\text { Atitudes } \\
\text { afetivas } \\
\text { calçados }\end{array}$} & $\begin{array}{l}\text { Eu gosto dos calçados } \\
\text { brasileiros. }\end{array}$ & AfetS1 \\
\hline & $\begin{array}{l}\text { Eu acho os calçados } \\
\text { brasileiros melhores do } \\
\text { que os de outros países. }\end{array}$ & AfetS2 \\
\hline & $\begin{array}{l}\text { Eu admiro os calçados } \\
\text { brasileiros. }\end{array}$ & AfetS3 \\
\hline & $\begin{array}{l}\text { Eu tenho simpatia pelos } \\
\text { calçados brasileiros. }\end{array}$ & AfetS4 \\
\hline \multirow{3}{*}{$\begin{array}{l}\text { Atitudes } \\
\text { conativas } \\
\text { calçados }\end{array}$} & $\begin{array}{l}\text { Eu compraria calçados } \\
\text { brasileiros. }\end{array}$ & ConaS1 \\
\hline & $\begin{array}{l}\text { Eu recomendaria calçados } \\
\text { brasileiros a um amigo. }\end{array}$ & ConaS2 \\
\hline & $\begin{array}{l}\text { Eu prefiro calçados } \\
\text { brasileiros a calçados de } \\
\text { outros países. }\end{array}$ & ConaS2 \\
\hline \multirow{4}{*}{$\begin{array}{l}\text { Atitudes } \\
\text { cognitivas } \\
\text { roupas }\end{array}$} & $\begin{array}{l}\text { As roupas brasileiras } \\
\text { possuem boa reputação }\end{array}$ & CogR1 \\
\hline & $\begin{array}{l}\text { As roupas brasileiras são } \\
\text { caras. }\end{array}$ & $\operatorname{Cog} R 2$ \\
\hline & $\begin{array}{l}\text { As roupas brasileiras têm } \\
\text { prestígio. }\end{array}$ & CogR3 \\
\hline & $\begin{array}{l}\text { As roupas brasileiras são } \\
\text { de alta qualidade. }\end{array}$ & $\operatorname{Cog} R 4$ \\
\hline
\end{tabular}

\begin{tabular}{|c|c|c|}
\hline \multirow{4}{*}{$\begin{array}{l}\text { Atitudes } \\
\text { afetivas } \\
\text { roupas }\end{array}$} & $\begin{array}{l}\text { Eu gosto das roupas } \\
\text { brasileiras. }\end{array}$ & AfetR1 \\
\hline & $\begin{array}{l}\text { Eu acho as roupas } \\
\text { brasileiras melhores do } \\
\text { que as de outros países. }\end{array}$ & AfetR2 \\
\hline & $\begin{array}{l}\text { Eu admiro as roupas } \\
\text { brasileiras. }\end{array}$ & AfetR3 \\
\hline & $\begin{array}{l}\text { Eu tenho simpatia pelas } \\
\text { roupas brasileiras. }\end{array}$ & AfetR4 \\
\hline \multirow{3}{*}{$\begin{array}{l}\text { Atitudes } \\
\text { conativas } \\
\text { roupas }\end{array}$} & $\begin{array}{l}\text { Eu compraria roupas } \\
\text { brasileiras. }\end{array}$ & ConaR1 \\
\hline & $\begin{array}{l}\text { Eu recomendaria roupas } \\
\text { brasileiras a um amigo. }\end{array}$ & ConaR2 \\
\hline & $\begin{array}{l}\text { Eu prefiro roupas } \\
\text { brasileiras a roupas de } \\
\text { outros países. }\end{array}$ & ConaR3 \\
\hline
\end{tabular}

Fonte: Elaborado pelos autores.

A população-alvo do estudo limitou-se à população de Stellenbosch, África do Sul. Para selecionar os elementos para compor a amostra, utilizouse a técnica de amostragem por conveniência, o que, segundo Viana (2011), justifica-se por sua simplicidade operacional e pela dificuldade associada à obtenção de amostras probabilísticas, considerando que normalmente não é possível obter uma estrutura de amostragem completa.

Para definir o tamanho da amostra, foram seguidas as recomendações de Hair Junior et al. (2009), que sugerem que, quando se objetivam aplicar técnicas estatísticas multivariadas para analisar os dados coletados, o tamanho da amostra deve ter entre 10 e 20 vezes a quantidade de variáveis incluídas na pesquisa. Considerando que as análises relativas ao efeito país de origem sobre as atitudes dos consumidores sulafricanos em relação a calçados e roupas de origem brasileira seriam realizadas separadamente e que cada uma delas contaria com 32 variáveis de pesquisa, definiu-se que a amostra deveria conter, pelo menos, 320 elementos.

Os indivíduos que fizeram parte da amostra da pesquisa e que responderam o questionário impresso, entregue pessoalmente por um dos pesquisadores, foram abordados nas ruas, especificamente em pontos da cidade de Stellenbosch com maior fluxo de pessoas, no Shopping Center da cidade e no campus da Stellenbosch University.

Os questionários que continham rasuras, mais de uma resposta em alguma questão ou ainda questões sem nenhuma resposta foram excluídos. Com isso, de um 
total de 381 questionários coletados, somente foram validados 321, atendendo as recomendações de Hair Junior et al. (2009) quanto ao tamanho da amostra.

A análise dos dados foi dividida em três etapas: primeiramente, as 21 variáveis relativas à imagem que os sul-africanos possuem do Brasil foram agrupadas em fatores por meio da Análise Fatorial Exploratória (AFE); na segunda etapa, as 11 variáveis que mensuravam as atitudes dos consumidores em relação às roupas brasileiras foram agrupadas por meio da $\mathrm{AFE}$ e os fatores obtidos foram utilizados, um a um, como variáveis dependentes em uma Análise de Regressão Múltipla; por fim, na terceira etapa, realizaram-se os mesmos procedimentos da etapa anterior, todavia, com as 11 variáveis que mensuravam as atitudes dos consumidores em relação aos calçados brasileiros.

Em cada análise de Regressão Múltipla realizada, as variáveis independentes foram os fatores provenientes da Análise Fatorial das variáveis relacionadas à imagem do Brasil, obtidos na primeira etapa da análise de dados. Por sua vez, os fatores provenientes das Análises Fatoriais das variáveis relativas às atitudes dos consumidores sul-africanos alternaram-se como variável dependente.

\section{Apresentação e Discussão dos Resultados}

Antes de apresentar os resultados das análises estatísticas realizadas, cabe apresentar a caracterização da amostra da pesquisa. Do total da amostra, $52,5 \%$ são indivíduos do gênero feminino e $47,5 \%$, do gênero masculino. Em relação à idade, indivíduos que possuem até 25 anos representaram aproximadamente $74,5 \%$ da amostra; indivíduos entre 26 e 33 anos, 18,5\%, e indivíduos com mais de 33 anos, aproximadamente $7 \%$. 82\% são solteiros e os outros $18 \%$ incluem casados, viúvos e outros status de estado civil. Quanto ao número de filhos, aproximadamente $82 \%$ da amostra são indivíduos que não possuem filhos, seguidos pelos indivíduos com apenas um filho $(8 \%)$ ou dois filhos $(8 \%) ; 2 \%$ possuem mais de dois filhos. Por fim, quanto à escolaridade, cerca de $5 \%$ dos indivíduos possuem ensino médio, $75 \%$ possuem ensino superior (completo ou cursando) e 20\%, pósgraduação.

\section{Análise Fatorial}

Os dados relacionados à imagem do Brasil junto aos consumidores sul-africanos foram, primeiramente, agrupados por meio da Análise Fatorial, com o intuito de reduzir as variáveis de pesquisa. Na primeira rodada de análise, todas as 21 variáveis foram incluídas na Análise Fatorial; entretanto, uma das variáveis, a AfetB1, apresentou comunalidade menor que $0,5 \mathrm{e}$, por isso, optou-se por excluí-la. Na segunda rodada de análise, todas as variáveis apresentaram valores maiores que 0,5 na matriz de comunalidades.

A partir do teste de esfericidade de Bartlett, podese constatar que, a um nível de significância de 5\%, rejeita-se a hipótese nula (alfa maior que p-valor: 0,05 $>0,000)$. Dessa forma, é possível afirmar que existem correlações suficientemente fortes entre as variáveis estudadas, justificando a aplicação da Análise Fatorial.

Realizou-se também o teste KMO (Kaiser Meyer Olkin), que apresentou o resultado de 0,833. Tal valor evidencia que a Análise Fatorial é uma técnica adequada para o conjunto de dados estudados, considerando que está próximo de um.

Analisando também a diagonal da matriz anti-imagem, verificou-se que nenhuma variável apresentou MSA (Measure of Sampling Adequacy) inferior a 0,7, valor recomendado como limítrofe inferior por Hair Junior et al. (2005). Sendo assim, todas são adequadas em relação à amostra coletada.

Dentre as soluções fatoriais que o SPSS retornou, foi adotada aquela que incluiu cinco fatores e foi capaz de explicar $62,59 \%$ da variância total dos dados coletados, superior à mínima ideal de $60 \%$, recomendada por Hair Junior et al. (2005). Os fatores obtidos podem ser visualizados no Quadro 02.

\section{Quadro 02: Fatores referentes à Imagem do Brasil.}

\begin{tabular}{|l|l|}
\hline Nome do fator & Variáveis \\
\hline $\begin{array}{l}\text { Fator Artes no Brasil } \\
\text { (FArtB) }\end{array}$ & $\begin{array}{l}\text { AvArt3, AvArt2, AvArt1, } \\
\text { AvArt4, AfetB2 }\end{array}$ \\
\hline $\begin{array}{l}\text { Fator Respeito pelo Brasil } \\
\text { (FRespB) }\end{array}$ & $\begin{array}{l}\text { Respe3, Respe4, Respe1, } \\
\text { Respe2, AfetB3 }\end{array}$ \\
\hline $\begin{array}{l}\text { Fator Comunicação do } \\
\text { Brasil (FComuB) }\end{array}$ & $\begin{array}{l}\text { AvCom2, AvCom1, } \\
\text { AvCom4, AvCom3 }\end{array}$ \\
\hline $\begin{array}{l}\text { Fator Produtos do Brasil } \\
\text { (FProdB) }\end{array}$ & $\begin{array}{l}\text { AvProd1, AvProd2, } \\
\text { AvProd3, AvProd4 }\end{array}$ \\
\hline $\begin{array}{l}\text { Fator Tecnologia do Brasil } \\
\text { (FTecB) }\end{array}$ & AvProd6, AvProd5 \\
\hline
\end{tabular}

Fonte: Elaborado pelos autores. 
Depois de agrupar as variáveis relacionadas à imagem do Brasil, agruparam-se as variáveis relacionadas às atitudes dos consumidores sul-africanos em relação a roupas de origem brasileira. As 11 variáveis analisadas apresentaram comunalidade maior que 0,5; por isso, nenhuma foi excluída.

Novamente, todos os testes realizados (esfericidade de Bartlett, KMO e MSA) apresentam resultados que validam a adequação da Análise Fatorial, considerando um nível de significância de 5\%. A solução fatorial adotada, apresentada no Quadro 03, incluiu três fatores e foi capaz de explicar 67,18\% da variância total dos dados coletados.

Quadro 03: Fatores relacionados às atitudes dos consumidores quanto a artigos de vestuário brasileiros.

\begin{tabular}{|l|l|}
\hline Nome do fator & Variáveis \\
\hline $\begin{array}{l}\text { Fator Atitudes Afetivas e } \\
\text { Conativas - Roupas Brasileiras } \\
\text { (FAfConR) }\end{array}$ & $\begin{array}{l}\text { ConaR1, ConaR2, } \\
\text { AfetR1, AfetR3, } \\
\text { AfetR4 }\end{array}$ \\
\hline $\begin{array}{l}\text { Fator Atitudes Cognitivas - } \\
\text { Roupas Brasileiras (FCogR) }\end{array}$ & $\begin{array}{l}\text { CogR2, CogR3, } \\
\text { CogR4, CogR1 }\end{array}$ \\
\hline $\begin{array}{l}\text { Fator Preferência por Roupas } \\
\text { Brasileiras (FPrefR) }\end{array}$ & ConaR3, AfetR2 \\
\hline
\end{tabular}

Fonte: Elaborado pelos autores.

Por fim, depois agrupar as variáveis relacionadas às atitudes dos consumidores sul-africanos em relação a artigos de vestuário brasileiros, foram agrupadas as variáveis relacionadas às atitudes desses mesmos consumidores quanto a sapatos de origem brasileira.

As 11 variáveis agrupadas apresentaram comunalidade maior que 0,5 e, por isso, não houve exclusões. Novamente, os testes de Bartlett, KMO e MSA apresentam resultados que justificam a realização da Análise Fatorial. A solução fatorial adotada, apresentada no Quadro 04, incluiu dois fatores e conseguiu explicar $64,88 \%$ da variância total dos dados coletados.
Quadro 04: Fatores relacionados às atitudes dos consumidores quanto a sapatos brasileiros.

\begin{tabular}{|l|l|}
\hline Nome do fator & Variáveis \\
\hline $\begin{array}{l}\text { Fator Atitudes Afetivas e Conativas - } \\
\text { Sapatos Brasileiros (FAfConS) }\end{array}$ & ConS3, AfetS4, \\
AfetS2, AfetS3, \\
ConaS2, \\
ConaS1
\end{tabular}

Fonte: Elaborado pelos autores.

\section{Efeito país de origem no segmento de vestuário na África do Sul}

Para testar o efeito país de origem no segmento de vestuário na África do Sul, realizou-se uma Análise de Regressão Múltipla; as variáveis independentes foram os fatores que mensuraram a imagem do Brasil junto aos consumidores sul-africanos (ver Quadro 02); por outro lado, como variáveis dependentes, foram utilizados, um a um, os fatores que mensuraram as atitudes desses consumidores perante as roupas brasileiras (ver Quadro 03).

Foram rodadas três análises de regressão, considerando que foram obtidos três fatores provenientes do agrupamento das variáveis que mensuraram as atitudes dos sul-africanos referentes às roupas brasileiras; todavia, somente duas delas foram efetivamente analisadas, à medida que a regressão que utilizou como variável dependente o fator FPrefR (Fator Preferência por Roupas Brasileiras) não obteve coeficiente de correlação maior do que 0,41 , evidenciando força de associação baixa (HAIR JUNIOR et al., 2005) em relação à imagem do Brasil perante os consumidores sul-africanos.

A primeira regressão analisada adotou como variável dependente o Fator Atitudes Afetivas e Conativas Roupas Brasileiras (FAfConR) e resultou em quatro modelos, dentre os quais se optou pelo modelo quatro, à medida que este apresentou maior coeficiente de determinação ajustado $(0,249)$.

Com isso, é possível afirmar que o modelo de regressão obtido explica $24,9 \%$ da variação nas atitudes afetivas e conativas dos consumidores sul-africanos em relação a peças de vestuário de origem brasileira.

\footnotetext{
${ }^{1}$ Delta é o nome fictício da empresa terceirizada que prestava serviços de limpeza e segurança para alfa, e que empregava todos os entrevistados como terceirizados.
} 
O Teste ANOVA realizado para este modelo específico apontou que existe regressão para ao menos uma das variáveis, já que a significância foi menor que 0,05 $($ sig. $=0,000)$. Nos testes de significância realizados para cada uma das variáveis incluídas no modelo quatro, os p-valores obtidos foram menores que 0,05 , evidenciando sua significância estatística.

Para verificar se o modelo quatro não apresentava multicolinearidade elevada entre as variáveis independentes, realizou-se o teste FIV (Fator de Inflação da Variância), a partir do qual se constatou que existe alguma associação entre as variáveis de previsão, mas não forte o suficiente para causar problemas (resultados obtidos foram menores que cinco, valor apontado por Hair Junior et al., 2005, como limítrofe superior para o teste). Em seguida, realizou-se o teste de Tolerância, cujos resultados foram maiores que o valor mínimo aceitável de 0,1 (HAIR JUNIOR et al., 2005), reforçando que não existe multicolinearidade significativa.

O modelo de regressão quatro pode ser representado da seguinte forma (a constante obtida foi aproximadamente zero e, por isso, não foi incluída na equação):

$$
\mathrm{Y}=0,365 \mathrm{X}_{1}+0,266 \mathrm{X}_{2}+0,171 \mathrm{X}_{3}+0,159 \mathrm{X}_{4}
$$

Sendo:

Y - Fator Atitudes Afetivas e Conativas - Roupas Brasileiras

$\mathrm{X}_{1}$ - Fator Artes no Brasil

$\mathrm{X}_{2}$ - Fator Produtos do Brasil

$\mathrm{X}_{3}$ - Fator Respeito pelo Brasil

$\mathrm{X}_{4}$ - Fator Comunicação do Brasil

A partir da análise do modelo de regressão obtido, constatou-se que a avaliação dos consumidores sulafricanos quanto às habilidades criativas e artísticas do Brasil e à qualidade dos produtos brasileiros, associada à importância e respeito que tais consumidores têm pelo Brasil, e aos esforços de comunicação que o Brasil desenvolve na África do Sul, influenciam positivamente as atitudes afetivas e conativas dos consumidores sul-africanos em relação às roupas de origem brasileira.

A segunda regressão analisada adotou como variável dependente o Fator Atitudes Cognitivas - Roupas Brasileiras (FCogR) e resultou em quatro modelos, dentre os quais se optou pelo modelo quatro, à medida que este apresentou maior coeficiente de determinação ajustado $(0,233)$.

A partir do valor encontrado para tal coeficiente, é possível afirmar que o modelo de regressão obtido explica 23,3\% da variação nas atitudes cognitivas dos consumidores sul-africanos em relação a peças de vestuário de origem brasileira.

O Teste ANOVA realizado para este modelo específico apontou que existe regressão para ao menos uma das variáveis, já que a significância foi menor que 0,05 $($ sig. $=0,000)$. Nos testes de significância realizados para cada uma das variáveis incluídas no modelo quatro, os p-valores obtidos foram menores que 0,05 , evidenciando sua significância estatística.

Para verificar se o modelo quatro não apresentava multicolinearidade elevada entreas variáveis de previsão, realizaram-se o teste FIV (Fator Inflação de Variância) e o teste de Tolerância. Ambos os testes apresentaram resultados dentro dos limites recomendados por Hair Junior et al. (2005), evidenciando a não existência de multicolinearidade significativa.

O modelo de regressão obtido pode ser representado da seguinte forma (a constante obtida foi aproximadamente zero e, por isso, não foi incluída na equação):

$$
Y=0,294 X_{1}+0,289 X_{2}+0,196 X_{3}+0,187 X_{4}
$$

Sendo:

Y - Fator Atitudes Cognitivas - Roupas Brasileiras

$\mathrm{X}_{1}$ - Fator Tecnologia do Brasil

$\mathrm{X}_{2}$ - Fator Produtos do Brasil

$\mathrm{X}_{3}$ - Fator Respeito pelo Brasil

$\mathrm{X}_{4}$ - Fator Comunicação do Brasil

A partir da análise do modelo de regressão obtido, constatou-se que a avaliação dos consumidores sulafricanos quanto às habilidades técnicas e ao avanço tecnológico brasileiro, associada à qualidade atribuída aos produtos oriundos do Brasil, ao respeito que tais consumidores têm pelo Brasil, e aos esforços de comunicação que o Brasil desenvolve na África do 
Sul, influenciam positivamente as atitudes cognitivas dos consumidores sul-africanos em relação às roupas de origem brasileira.

Analisando os dois modelos de regressão descritos, pode-se afirmar que as atitudes cognitivas, conativas e afetivas dos consumidores da África do Sul em relação às peças de vestuário de origem brasileira são influenciadas positivamente pela avaliação que tais consumidores fazem do Brasil. Tal constatação vem ao encontro dos resultados obtidos por Phillips, Asperin e Wolfe (2013), que apontam que as atitudes dos consumidores são afetadas pelo efeito país de origem.

Além disso, os resultados obtidos corroboram as conclusões de Parkvithee e Miranda (2012) de que, no segmento de moda, especificamente em categorias de produtos como camisetas, existe relação entre a avaliação que os consumidores fazem acerca dos produtos e a imagem associada ao país onde estes foram produzidos.

\section{Efeito país de origem no segmento de calçados na África do Sul}

Para testar o efeito país de origem no segmento de calçados na África do Sul, realizou-se uma Análise de Regressão Múltipla; as variáveis independentes foram os fatores que mensuraram a imagem do Brasil junto aos consumidores sul-africanos (ver Quadro 02); por outro lado, como variáveis dependentes, foram utilizados, um a um, os fatores que mensuraram as atitudes desses mesmos consumidores em relação aos calçados brasileiros (ver Quadro 04).

Foram rodadas duas análises de regressão, considerando que foram obtidos dois fatores provenientes da Análise Fatorial das variáveis que mensuraram as atitudes referentes aos calçados brasileiros; todavia, somente uma delas foi efetivamente analisada, à medida que a regressão que utilizou como variável dependente o fator FAfConS (Fator Atitudes Afetivas e Conativas - Sapatos Brasileiros) não obteve coeficiente de correlação maior do que 0,41 , evidenciando força de associação baixa (HAIR JUNIOR et al., 2005) em relação à imagem do Brasil perante os consumidores sul-africanos.

A regressão analisada adotou como variável dependente o Fator Atitudes Cognitivas - Sapatos Brasileiros (FCogS) e resultou em quatro modelos, dos quais se optou pelo modelo quatro, à medida que este apresentou maior coeficiente de determinação ajustado $(0,235)$.

A partir do valor encontrado para tal coeficiente, é possível afirmar que o modelo de regressão obtido explica 23,5\% da variação nas atitudes cognitivas dos consumidores sul-africanos em relação aos calçados de origem brasileira.

O Teste ANOVA realizado para este modelo específico apontou que existe regressão para ao menos uma das variáveis, já que a significância foi menor que 0,05 (sig. $=0,000)$. Nos testes de significância realizados para cada uma das variáveis incluídas no modelo quatro, os p-valores obtidos foram menores que 0,05 , evidenciando sua significância estatística.

Para verificar se o modelo quatro não possui multicolinearidade elevada entre as variáveis independentes, realizaram-se o teste FIV (Fator Inflação de Variância) e o teste de Tolerância. Novamente, ambos os testes apresentaram resultados que evidenciaram a não existência de multicolinearidade significativa.

O modelo de regressão obtido pode ser representado da seguinte forma (a constante obtida foi aproximadamente zero e, por isso, não foi incluída na equação):

$$
\mathrm{Y}=0,361 \mathrm{X}_{1}+0,270 \mathrm{X}_{2}+0,166 \mathrm{X}_{3}+0,118 \mathrm{X}_{4}
$$

Sendo:

Y - Fator Atitudes Cognitivas - Sapatos Brasileiros

$\mathrm{X}_{1}$ - Fator Produtos do Brasil

$\mathrm{X}_{2}$ - Fator Artes no Brasil

$\mathrm{X}_{3}$ - Fator Tecnologia do Brasil

$\mathrm{X}_{4}$ - Fator Respeito pelo Brasil

A partir da análise do modelo de regressão obtido, constatou-se que a avaliação dos consumidores sulafricanos quanto à qualidade dos produtos brasileiros, às habilidades criativas e artísticas do Brasil e ao avanço tecnológico brasileiro, associada à importância e respeito que tais consumidores atribuem ao Brasil, influenciam positivamente as atitudes cognitivas dos consumidores sul-africanos em relação aos calçados oriundos do Brasil.

Novamente, destaca-se que esses resultados estão alinhados àqueles obtidos por Phillips, Asperin e Wolfe 
(2013), referentes à influência que a imagem do país de origem dos produtos exerce sobre as atitudes dos consumidores. Ademais, os resultados obtidos nesta pesquisa vêm ao encontro das conclusões de Giraldi e Carvalho (2009), que indicam que, no segmento calçadista, os consumidores são influenciados pela imagem do país em que os calçados foram fabricados.

\section{Análise conjunta dos resultados}

Analisando conjuntamente os três modelos de regressão obtidos, percebe-se que o efeito país de origem que a imagem brasileira exerce sobre os consumidores sul-africanos influencia as atitudes dos mesmos no nível cognitivo ou racional, no segmento de calçados, e nos níveis cognitivo, afetivo e conativo, no segmento de vestuário.

Especificamente no segmento de calçados, dentre todos os aspectos que compõem a imagem que os sul-africanos possuem do Brasil, apenas os esforços brasileiros de comunicação na África do Sul não se mostraram relevantes como antecedentes das atitudes cognitivas dos consumidores de tal país. Para a formação das atitudes afetivas e conativas, não foi possível confirmar a influência da imagem do Brasil.

Por outro lado, no segmento de vestuário, todos os aspectos que compõem a imagem do Brasil mostraramse relevantes enquanto antecedentes das atitudes dos consumidores da África do Sul. Entretanto, apenas as atitudes afetivas e conativas desses consumidores são influenciadas pelas habilidades criativas e artísticas do Brasil, ao passo que somente as atitudes cognitivas (nível racional) são influenciadas pelo avanço tecnológico brasileiro.

Analisando conjuntamente o segmento de vestuário e calçados, adotando-os como representativos do setor de moda, considera-se que a avaliação dos consumidores sul-africanos quanto ao avanço tecnológico brasileiro, às habilidades criativas e artísticas do Brasil e à qualidade dos produtos brasileiros, associada à importância e respeito que tais consumidores atribuem ao Brasil e aos esforços de comunicação que o Brasil desenvolve na África do Sul, influenciam a avaliação dos sul-africanos e sua pré-disposição em adquirirem produtos brasileiros da indústria da moda.

Destaca-se que tal constatação mostra-se alinhada aos estudos de Giraldi e Carvalho (2009), Parkvithee e Miranda (2012), Godey et al. (2012), Phillips, Asperin e Wolfe (2013), Lee, Lee e Lee (2013) e Berry et al. (2015) e Silva et al. (2015), que demonstraram o impacto do efeito país de origem sobre o comportamento dos consumidores em diferentes segmentos de produtos.

Além disso, os resultados aqui obtidos permitem corroborar que a imagem de um país, que influencia as atitudes dos consumidores em relação aos produtos lá fabricados (PHILLIPS; ASPERIN; WOLFE, 2013), deve ser analisada de forma multidimensional, considerando aspectos como avanço tecnológico, desenvolvimento artístico-cultural e projeção políticoeconômica (CANTO-GUINA; GIRALDI, 2012; ROTH; DIAMANTOPOULOS, 2009).

\section{Considerações Finais}

Com base nos resultados obtidos nessa pesquisa, foi possível constatar que a imagem que os consumidores sul-africanos possuem do Brasil influencia as atitudes dos mesmos em relação às roupas e calçados de origem brasileira.

Tal constatação evidencia que, para que a indústria da moda brasileira consiga efetivamente penetrar nos mercados africanos, especialmente na África do Sul, é importante que haja um esforço consciente e direcionado para formar nos consumidores de lá uma imagem positiva a respeito do Brasil.

Para isso, primeiramente devem ser planejadas ações de comunicação integradas cujo foco extrapole a identidade de uma marca específica, visando projetar uma imagem favorável associada ao Brasil. Aqui, cabe a ressalva de que os programas de comunicação focados em marcas específicas não devem ser menosprezados e são, sim, importantes para garantir a penetração das empresas brasileiras no mercado sul-africano. Entretanto, faz-se necessário primeiro estimular o desenvolvimento de atitudes positivas nos sul-africanos em relação aos calçados e roupas brasileiras de forma genérica, o que perpassa pela projeção de uma imagem positiva do país de origem desses produtos.

Idealmente, a imagem a ser desenvolvida pelo Brasil na África do Sul deve projetar uma ideia de superioridade em relação à competência técnica e criativa da indústria brasileira, assim como de domínio de tecnologias de ponta, aliada a um status de importância reconhecida no cenário internacional.

Caso esses esforços de comunicação sejam bemsucedidos perante o mercado da África do Sul, os 
consumidores sul-africanos tendem a (1) relacionar mais benefícios à compra de roupas e calçados brasileiros - nível cognitivo das atitudes; (2) associar emoções positivas às marcas brasileiras de roupas - nível afetivo das atitudes; e (3) desenvolver maior pré-disposição para a compra desses produtos - nível conativo das atitudes.

Por outro lado, refletindo acerca das múltiplas dimensões que possui a imagem de um país, percebe-se que, além de direcionar esforços de comunicação para formar uma imagem positiva do Brasil nos consumidores sulafricanos, é essencial que se busque maior projeção econômica e política internacionalmente, o que tende a aumentar o respeito que tais consumidores nutrem pelo país e, consequentemente, favorecer a penetração dos produtos nacionais nos mercados da África do Sul.

Da mesma forma, é importante que a economia brasileira direcione investimentos para ampliar o desenvolvimento tecnológico do país e seu potencial artístico, com o intuito de se consolidar como referência tecnológica e criativa perante mercados internacionais.

Concluindo, destaca-se que, para que haja avanços mais significativos da penetração da indústria da moda brasileira nos mercados da África do Sul, é importante que o Brasil (1) invista em campanhas internacionais de comunicação, reforçando seu papel de destaque no cenário internacional, (2) aumente sua projeção econômica e política a nível internacional e (3) amplie seu desenvolvimento tecnológico e potencial criativo. Todas essas ações tendem a impactar positivamente a imagem do país perante os sul-africanos e, consequentemente, torná-los mais interessados pelas roupas e calçados de origem brasileira.

Sendo assim, é possível concluir que a crescente internacionalização da indústria da moda brasileira depende, além de seus próprios esforços e investimentos, de uma política nacional de consolidação tecnológica e projeção internacional.

Para finalizar, sugere-se, para estudos futuros, que a presente pesquisa seja ampliada para outros mercados africanos, com o intuito de testar se os resultados aqui obtidos têm validade em outros países daquele continente. Adicionalmente, torna-se relevante ampliar esta investigação a outras categorias de produtos, buscando-se confirmar o efeito país de origem que a imagem do Brasil exerce perante os sul-africanos em diferentes setores, além da indústria da moda.

\section{Referências}

AGARWAL, S.; SIKRI, S. Country image:

consumer evaluation of product category extension.

International Marketing Review, v. 13, n. 4, p. 44 55, 1996.

AMINE, L. S. Country-of-origin, animosity and consumer response: marketing implications of antiAmericanism and Francophobia. International Business Review, v. 17, n. 4, p. 402-422, 2008.

BERRY, C.; MUKHERJEE, A.; BURTON, S.; HOWLETT, E. A COOL effect: the direct and indirect impact of country-of-origin disclosures on purchase intentions for retail food products. Journal of Retailing, v. 91, n. 3, p. 533-542, 2015.

BILKEY, W. J.; NES, E. Country-of-origin effects on product evaluation. Journal of International Business Studies, v. 13, n. 1, p. 89-99, 1982.

CANTO-GUINA, F. T.; GIRALDI, J. M. E. Um ensaio sobre os construtos imagem de país e efeito país de origem. Revista Brasileira de Gestão e Desenvolvimento Regional, v. 8, n. 2, p. 319-343, 2012.

CORDELL, V. V. Interaction effects of country of origin with branding, price and perceived performance risk. Journal of International Consumer Marketing, v. 5, n. 2, p. 5-18, 1993.

DROZDENKO, R.; JENSEN, M. Translating country-of-origin effects into prices. Journal of Product and Brand Management, v. 18, n. 5, p. 371-378, 2009.

GIRALDI, J. M. E.; CARVALHO, D. T. A imagem do Brasil no exterior e sua influência nas intenções de compra. RAC-Eletrônica, v. 3, n. 1, p. 22-40, 2009 .

GIRALDI, J. M. E.; IKEDA, A. A.; CARVALHO, D. T. Atitudes em relação a produtos brasileiros: uma investigação com estudantes holandeses. Revista de Administração Mackenzie, v. 9, n. 3, p. 11-37, 2008.

GODEY, B.; PEDERZOLI, D.; AIELLO, G.; DONVITO, R.; CHAN, P.; OH, H.; SINGH, R.; SKOROBOGATYKH, I. I.; TSUCHIYA, J.; WEITZ, B. Brand and country-of-origin effect on consumers' decision to purchase luxury products.

Journal of Business Research, v. 65, p. 1461-1470, 2012.

HAIR JUNIOR, J. F.; BLACK, W. C.; BABIN, B. J.; ANDERSON, R. E.; TATHAM, R. L. Análise 
multivariada de dados. 6. ed. Porto Alegre:

Bookman, 2009.

HAIR JUNIOR, J. F.; BABIN, B. J.; MONEY, A. R; SAMOUEL, P. Fundamentos de métodos de pesquisa em administração. Porto Alegre: Bookman, 2005.

$\mathrm{HAN}, \mathrm{H}$. The investigation of country-of-origin effect using Taiwanese consumers' perceptions of luxury handbags as example. Journal of American Academy of Business, v. 15, n. 2, p. 66-72, 2010.

HOFFMANN, S.; MAI, R.; SMIRNOVA, M. Development and validation of a cross-nationally stable scale of consumer animosity. Journal of Marketing Theory and Practice, v. 19, n. 2, p. 235251, 2011.

HONG, S. T.; KANG, D. K. Country of origin influences on product evaluations: the impact of animosity and perceptions of industriousness brutality on judgments of typical and atypical products. Journal of Consumer Psychology, v. 16, n. 3, p. 232-239, 2006.

HULLANG, J.; TODIÑO, H. S.; LECRAW, D. J. Country-of-origin effects on sellers' price premiums in competitive Philippine markets. Journal of International Marketing, v. 4, n. 1, p. 57-79, 1996.

KABADAYI, S.; LERMAN, D. Made in China but sold at FAO Schawarz: country-of-origin effect and trusting beliefs. International Marketing Review, v. 28, n. 1, p. 102-126, 2011.

KUMARA, S.; CANHUA, K. Perceptions of country of origin: an approach to identifying expectations of foreign products. Journal of Brand Management, v. 17 , n. 5 , p. $343-353,2010$.

LEE, D.; GANESH, G. Effects of partitioned country image in the context of brand image and familiarity: a categorization theory perspective.

International Marketing Review, v. 16, n. 1, p. 1839, 1999.

LEE, J. K.; LEE, B.K.; LEE, W.N. Country-of-origin fit's effect on consumer product evaluation in crossborder strategic brand alliance. Journal of Business Research, v. 66, n. 3, p. 354-363, 2013.

LEE, W. J.; PHAU, I.; ROY, R. "Bonds" or "Calvin Klein" down-under: consumer ethnocentrism and brand country origin effects towards men's underwear. Journal of Fashion Marketing and Management, v. 17, n. 1, p. 65-84, 2013.
MEHMET, T.; PIRTINI, S.; ERDEM, Y. C. The perceived country of origin images in Turkey. International Business and Economies Research Journal, v. 9, n. 8, p. 127-133, 2010.

NAGASHIMA, A. A comparison of Japanese and US attitudes toward foreign products. Journal of Marketing, v. 34, n. 1, p. 68-74, 1970.

PARKVITHEE, N.; MIRANDA, M. J. The interaction effect of country-of-origin, brand equity and purchase involvement on consumer purchase intentions of clothing labels. Asia Pacific Journal of Marketing and Logistics, v. 24, n. 1, p. 7-22, 2012.

PEDUZZI, P. Parcerias com África podem ajudar Brasil a amenizar efeitos da crise, diz APEX. Agência Brasil. Disponível em: < http://www.ebc.com.br/noticias/ economia/2015/10/parcerias-com-africa-podemajudar-brasil-amenizar-efeitos-da-crise-diz > . Acesso em: 20 nov. 2015.

PHILLIPS, W. L.; ASPERIN, A.; WOLFE, F. Investigating the effect of country image and subjective knowledge on attitudes and behaviors: U.S. Upper Midwesterners' intentions to consume Korean Food and visit Korea. International Journal of Hospitality Management, v. 32, n. 1, p. 49-58, 2013.

POON, P.; EVANGELISTA, F.; ALBAUM, G. Attitudes of migrants towards foreign-made products: an exploratory study of migrants in Australia. Journal of Consumer Marketing, v. 27, n. 1, p. 35-42, 2010.

ROTH, M. S.; DIAMANTOPOULOS, A. Advancing the country image construct. Journal of Business Research, v. 62, n. 7, p. 726-740, 2009.

SAMILI, A. C. International Consumer Behavior in the $21^{\text {st }}$ century: impact on marketing strategy development. New York: Springer, 2013.

SHIMP, T. A.; SHARMA, S. Consumer ethnocentrism: construction and validation of the CETSCALE. Journal of Marketing Research, v.24, n. 3, p. 280-289, 1987.

SILVA, S. M.; LAZZARI, F.; MILAN, G. S.; EBERLE, L. O efeito país de origem e o comportamento do consumidor em relação a vinhos. REAd - Revista Eletrônica de Administração, v. 80, n. 1, p. 89-112, 2015.

VIANA, A. B. N. Pesquisa quantitativa aplicada ao varejo. In: MERLO, E. M. (Org.). Administração de varejo com foco em casos brasileiros. Rio de Janeiro: LTC, 2011. 